\title{
Birinci Basamak Sağlık Hizmetlerinde Çalışan Sağlıkçıların Sağlıklarına ve Çalıştıkları Ortamdaki Risk Etmenlerine İlişkin Değerlendirilmesi
}

\author{
Makbule Tokur Kesgin ${ }^{\oplus}$, Betül Bay²®
}

${ }^{1}$ Abant İzzet Baysal Üniversitesi Sağlık Yüksekokulu, Halk Sağlığı Hemşireliği, Bolu, Türkiye

2Zekai Tahir Burak Kadın Sağlığı Eğitim ve Araştırma Hastanesi, Yenidoğan Yoğun Bakım, Ankara, Türkiye

Makbule Tokur Kesgin, Yard. Doç. Dr. Betül Bay, Uzm. Hemşire

İletişim:

Uzm. Hemşire Betül Bay

Zekai Tahir Burak Kadın Sağlı̆ı Eğitim ve

Araştırma Hastanesi, Yenidoğan Yoğun Bakım,

Ankara, Türkiye

Tel: +905314030667

E-Posta: betulbay6@gmail.com

Gönderilme Tarihi : 12 Şubat 2018

Revizyon Tarihi : 14 Haziran 2018

Kabul Tarihi $\quad$ : 07 Temmuz 2018
ÖZET

Amaç: Çalışma Bolu il merkezinde birinci basamak sağlık hizmetlerinde çalışan sağıkçıların sağlıklarııın ve çalıştıkları ortamdaki risk etmenlerine ilişkin değerlendirilmesini amaçlamaktadır.

Yöntem: Araştırmanın evreni

Araştırmanın yürütüldü̆ğü Bolu Halk Sağlgğı Müdürlügüu'ne bağlı Bolu il merkezindeki 1 toplum sağı̆̆ı̆ merkezi ve 29 aile sağlığı merkezinde çalısan 150 sağlık personeli araş̧ırmanın evrenini oluşturmuş̧ur.

Araştırmanın örneklemi: Araştırmanın anlamlıık düzeyi \%5, güç \%90 sağık çalışanlarının son bir yıl içinde risklerle karşılaşma prevalansı \%85 kabul edilerek örneklem büyüklüğï 96 olarak bulunmuştur. Basit rastgele örneklem yöntemi kullanılarak araştırmaya katılıayı kabul eden 96 sağık çalışanına ulaşıımıştır.

Veri toplama araçları: Çalışmayı kabul eden 96 sağlık çalısanına 2015 Mayıs-2016 Temmuz tarihlerinde araştırmacılar tarafından literatür incelenerek oluşturulan veri toplama formu kullanııııştır.

Verilerin değerlendirilmesi: Verilerin değerlendirilmesinde kişisel bilgilerin yorumInmasında sayı ve yüzde testi kullanıımıştır.

Bulgular: Sağılık çalışanlarının sosyo-demografik ve mesleki özelliklerine bakııdı̆ı̆nda \%43.8' 34-41 yaş aralığında, \%84.4’ü kadındır. Ankete katılanları \% $47.9^{\prime}$ u ebe, $\% 27.1^{\prime \prime}$ hekimdir. Katılımclar işe bağlı hastalık geçirme durumlarııı \%15.6 olarak belirtirken, \%11.5i dermatit, \%4.2'si depresyon, \%5.2'si alerjik rinit, \%4.2'si boyun fitı̆ı̆, \%3.1'i varis geçirmiştir.

Sonuçlar: Birinci basamak sağık çalışanları çalıştıkları kurumda ruhsal, ergonomik sorunlar yaşadıkları, çoğunlukla kesici-delici alet yaralanmasına maruz kaldıkları belirlenmişţir. Çalışlan kurumların mesleki risklerle ilgili önlem alma durumu orta düzeydedir ve kurumların büyük çoğunluğunda iş sağlığı ve güvenliğinden sorumlu ekip yoktur. Sağlık çalş̧anlarııın psikolojik şiddete maruz kalma oranları önemli düzeydedir.

Anahtar sözcükler: Birinci basamak sağlık hizmetleri, mesleki hastalıklar, risk faktörleri, sağlık çalışanları

DETERMINATION OF THE HEALTH OF HEALTH PROFESSIONALS WORKING IN THE PRIMARY HEALTH AND THE RISK FACTORS IN WORK ENVIRONMENT

ABSTRACT

Aim: The aim of this study is to evaluate the health of health care workers working in primary health care services in Bolu province and their risk factors in the environment.

Methods: The universe of our research is a one community health center in Bolu and 150 medical staff working in 29 family health centers affiliated with the Bolu Public Health Directorate where the research was conducted.

Sample of the study: The survey's significance level was 5\%, the strength(power) was $90 \%$, and the sample size was found to be 96 with the prevalence of risks encountered by health workers in the last one year being $85 \%$. A total of 96 health workers who agreed to participate in the study were reached using the simple random sampling method.

Data collection tools: The data collection form created by examining the literature by researchers from May 2015 to July 2016 was used for 96 health workers who accepted to work.

Evaluation of data: In the evaluation of the data, number and percentage tests were used to interpret the personal information.

Results: When the socio-demographic and occupational characteristics of health workers were examined, $43.8 \%$ were in the age range of $34-41$ years, $84.4 \%$ were females. $47.9 \%$ of the participants were midwives and $27.1 \%$ were physicians. Participants reported work-related illnesses as $15.6 \%, 11.5 \%$ as dermatitis, $4.2 \%$ as depression, $5.2 \%$ as allergic rhinitis, $4.2 \%$ as herniated cervical disk and $3.1 \%$ as varicose veins. .

Conclusions: Primary health care workers have experienced mental and ergonomic problems in the institution/s they are working in, and they are mostly exposed to cutting-piercing injuries. Working establishments are at a moderate level to take actions against occupational risks and there is no team responsible for occupational health and safety in the vast majority of institutions. Psychological violence exposure rates of health workers are significant.

Keywords: Primary health care, occupational health, risk factors, health personnel 
$\mathbf{U}$ luslararası Çalışma Örgütü ve Dünya Sağlık Örgütü, iş sağlığını bütün mesleklerde bedensel, ruhsal ve sosyal yönden iyilik hallerinin üst düzeyde tutulması, sürdürülmesi ve geliştirilmesi olarak tanımlanmıştır. Her çalışanın sağlık hizmeti alması, sağlıklı ve güvenli ortamda çalışması insan olmanın getirdiği bir haktır. Bunun yanında çalışmak, üretmek, kazanmak ve sosyal yaşamı olumlu koşullarda sürdürebilmek de çalışanlar açısından önemlidir. Çalışmak ve üretmek çalışanlar için pek çok olumlu katkıda bulunuyor olsa da yapılan her iş özelliğine bağlı olarak içinde çeşitli riskler barındırmaktadır (1).

Sağlık sektöründe çalışanların da alanlarına özgü karşı karşıya kaldıkları tehlikeler ve riskler mevcuttur. Çalışma ve Sosyal Güvenlik Bakanlığı tarafından 2017 yılında güncellenen "Işs sağlığı ve güvenliğine ilişkin işyeri tehlike sınıfları tebliğine" göre sağlık sektöründe verilen hizmetler "çok tehlikeli" ve "tehlikeli" sınıflarında yer almaktadır (2). Sağlık çalışanlarının maruz kaldıkları tehlike ve riskler Dünya Sağlık Örgütü tarafından 7 başlıkta incelenmektedir; fiziksel tehlikeler, kimyasal tehlikeler, biyolojik tehlikeler, ergonomik tehlikeler, psikososyal tehlikeler, yangın ve patlama tehlikeleri, elektrik tehlikeleridir (3).

Fiziksel ve ergonomik tehlikeler; sağlık çalışanları gürültü, aydınlatma, havalandırma, radyasyon, servis düzeninin ve malzemelerin sağlık çalışana uygun tasarlanmaması, düzensiz ve uzun çalışma saatleri, çalışma-dinlenme süreleri arasındaki dengenin sağlanamaması nedeniyle fiziksel ve ergonomik tehlikelere maruz kalmaktadırlar $(4,5)$. Bu tehlikelerin iş kazalarına, kas- iskelet sistemi rahatsızlıklarına, tıbbi hatalarda artışa, iş performansında düşüşe, iş yükünde artışa neden olduğu belirtilmiştir $(6,7)$.

Kimyasal tehlikeler; sağlık hizmetlerinde sterilizasyon ve dezenfeksiyon amacıyla kullanılan maddelerin solunum yolu hastalıklarına, alerji ve deri tahribatına; antineoplastik maddelerin üreme sağlığında bozulmalara, konjenital anomalilere, mutojenik değişikliklere neden olduğu bildirilmiştir (8-10).

Biyolojik tehlikeler; vücut sıvıları, kan ya da bunlarla kontamine olmuş malzemeler sebebiyle sağlık çalışanları bulaşıcı hastalık riskine maruz kalmaktadır (11). Hepatit B ile enfekte sağlık bakım çalışanlarının \%37 sinde enfeksiyon mesleksel kaynaklıdır (3). Mesleki bulaşma sonucu oluşan HIV enfeksiyonlarının önemli bir kısmının nedeni iğne batması sonucu oluşan yaralamalardır ve pratik ve düşük maliyetli önlemlerle bu yaralanmaların önüne geçilebileceği belirtilmektedir $(3,11)$.
Psikososyal tehlikeler; işyerinde düşük örgütsel ve sosyal destek, uygun işin uygun kişi tarafından yapılmaması, hasta, hasta yakını, çalışma arkadaşları ve amirler tarafından uygulanan şiddet davranışları, sağlık kurumlarında güvenlik önlemlerinin yetersizliği, eğitim olanaklarının yetersizliği, mesleki gelişim fırsatlarının olmaması/az olması, görev tanımındaki belirsizlikler nedeniyle sağlık çalışanları psikososyal tehlike ve risklere maruz kalmaktadır (12-14).

Dünya Sağlık Örgütü verilerine göre her gün 59 milyon sağlık bakım çalışanı sağlık ve güvenliklerini tehdit eden bir sorunla karşı karşıya kalmaktadır. Ayrıca iklim değişikliği, salgınlar, küreselleşme, göçler, kronik hastalıkların artması da sağlık çalışanlarının iş yükünü artırmaktadır $(15,16)$. Bu açıdan kapsamlı ve sürekli bir sağlık hizmet sunumu için birinci basamak sağlık çalışanlarının sağlığına verilen önem de giderek artmaktadır. Ancak birinci basamak sağlık hizmetlerinde çalışan sağlık personelleri bilindik risk etmenlerinin yanında hastalıkların erken teşhisi, bağışıklama, danışmanlık, aile planlaması, çevreye yönelik koruyucu hizmetler gibi pek çok konuda toplumdaki bireylerle ilk karşılaşılan birim olması nedeniyle sağlıklarını tehdit eden birinci basamağa ait risk etmenlerine de maruz kalmaktadır (16).

Yapılan çalışmalarda hizmet içi eğitimlerin düzenli olarak yapılması, bağışıklama, uygun ergonomik tasarımlar, koruyucu ekipman kullanımı, güvenli raporlama sistemleri geliştirilmesinin ve düzenli sağlık taramalarının sağlık çalışanlarının sağlığı üzerinde olumlu etkiye sahip olacağı belirtilmiştir $(4,6)$. Sağlık hizmetlerinin yürütülmesinden, bireyin, ailenin ve toplumun sağlığının korunmasından, geliştirilmesinden; hastalık halinde iyileştirmeye yönelik sorumlulukları olan sağlık çalışanlarının görev ve sorumluluklarını yerine getirebilmeleri için tam bir iyilik halinde olmaları için risk etmenlerinin belirlenmesi önemlidir. Risklerin belirlenmesi, ortaya çıkabilecek zararların önceden tahmin edilmesini ve alınacak önlemlerin tespit edilmesini de kolaylaştıracaktır. Böylece birinci basamak sağlık hizmetlerinde çalışanların güvenli ortamlarda, sağlıklı ve verimli bir şekilde çalışmalarına da katkı sağlanmış olacaktır. Bu araştırma sağlık çalışanlarının çalışma ortamındaki risk etmenlerinin belirlenmesine katkıda bulunacaktır.

\section{Araştırmanın amacı}

Bu çalışmada Bolu il merkezinde birinci basamak sağlık hizmetlerinde çalışan sağlıkçıların sağlıklarına ve çalıştıkları ortamdaki risk etmenlerine ilişkin değerlendirilmesi amaçlanmıştır. 


\section{Yöntem}

\section{Araştırmanın evreni}

Araştırmanın yürütüldüğü Bolu Halk Sağlığı Müdürlüğü'ne bağlı Bolu merkezdeki 1 toplum sağlığı merkezi ve 29 aile sağlığı merkezinde çalışan 150 sağlık personeli araştırmanın evrenini oluşturmuştur.

\section{Araştırmanın örneklemi}

Araştırmanın anlamlılık düzeyi $\% 5$, güç $\% 90$ sağlık çalışanlarının son bir yıl içinde risklerle karşılaşma prevalansı \%85 kabul edilerek örneklem büyüklüğü 96 olarak bulunmuştur $(5,17)$. Basit rastgele örneklem yöntemi kullanılarak araştırmaya katılmayı kabul eden 96 sağlık çalışanına ulaşılmıştır.

\section{Veri toplama araçları}

Çalışmayı kabul eden 96 sağlık çalışanına 2015 Mayıs-2016 Temmuz tarihlerinde araştırmacılar tarafından literatür incelenerek oluşturulan veri toplama formu kullanılmıştır.

\section{Verilerin değerlendirilmesi}

Verilerin değerlendirilmesinde kişisel bilgilerin yorumlanmasında sayı ve yüzde testi kullanılmıştır.

\section{Bulgular}

Sağlık çalışanlarının sosyo-demografik ve mesleki özelliklerine bakıldığında \%43,8'i 34-41 yaş aralığında, \%84,4'ü kadındır. Ankete katılanların \%47,9'u ebe, \%27,1'i hekimdir. Sağlık çalışanlarının \%39,6'sı lisans mezunudur. Kurumda çalışma yıllarına bakıldığında \%42,7'si 8-11 yıl arasında çalıştığı belirlenmiştir.

Tablo1'de sağlık çalışanlarının sağılı durumları ile ilgili bazı özellikler görülmektedir. Buna göre; sağlık çalışanlarının \%27,1'inin kronik hastalığı var, \%29,2'sinin kullandığı bir ya da daha fazla ilaç vardır. Katılımcıların BCG $(\% 65,6)$, hepatit B $(\% 89,6)$, tetanoza $(\% 89,6)$ karşı bağışıklığı bulunmaktadır.

Tablo 2'de sağlık çalışanlarının birinci basamakta kaza/ yaralanma ve işe bağlı hastalık geçirme durumlarına ilişkin özellikler görülmektedir. Katılımcıların \%12,5'i 1. Basamakta kaza yaralanma geçirmiş, \%90,9'u kesici-delici alet yaralanması geçirmiş, \%9,1'i ambulansla vakaya giderken kaza geçirmiş, kaza yaralanma geçirdikten sonra \%33,3'ü hiçbir şey yapmazken, \%41,7'si gerekli tahlilleri yaptırmıştır. Katılımcılar işe bağlı hastalık geçirme durumlarını \%15,6 olarak belirtirken, \%11,5'i dermatit geçirdiklerini, \%4,2'si depresyon geçirdiklerini, \%5,2'si alerjik rinit geçirdiklerini, \%4,2'si boyun fıtığı geçirdiklerini, $\% 3,1^{\prime} \mathbf{i}$ varis geçirdiklerini, \%1,0'i pnömoni geçirdiklerini belirtmişlerdir.
Tablo1. Sağlık çalışanlarının sağlık durumları ile ilgili bazı özellikler

\begin{tabular}{lllcc}
\hline Sağık durumları & & & Sayı & Yüzde \\
\hline Kronik hastalık varlığı & Evet & & 26 & 27,1 \\
& Hayır & & 70 & 72,9 \\
İlaç kullanma durumu & Evet & & 29 & 29,2 \\
& Hayır & & 67 & 70,8 \\
Bağışıklanma durumu & Bcg & Evet & 64 & 65,6 \\
& & Hayır & 32 & 34,4 \\
& Hepatit B & Evet & 86 & 89,6 \\
& & Hayır & 10 & 10,4 \\
& Tetanos & Evet & 86 & 89,6 \\
& & Hayır & 10 & 10,4
\end{tabular}

Tablo 2. Sağlkk çalışanlarının birinci basamakta kaza/yaralanma ve işe bağlı hastallk geçirme durumlarna ilişkin özellikler

Birinci basamakta kaza/yaralanma, işe bağlı hastalık geçirme durumları

\begin{tabular}{|c|c|c|c|}
\hline & & Sayı & Yüzde \\
\hline \multirow{2}{*}{$\begin{array}{l}\text { Birinci Basamakta Kaza/Yaralanma, } \\
\text { İşe Bağlı Hastalık Geçirme Durumu }\end{array}$} & Evet & 12 & 12,5 \\
\hline & Hayır & 84 & 88,5 \\
\hline \multirow[t]{2}{*}{ Geçirilen kaza/yaralanmanın türü } & Kesici-delici alet & 11 & 90,9 \\
\hline & $\begin{array}{l}\text { Ambulans ile } \\
\text { vakaya giderken } \\
\text { kaza geçirme }\end{array}$ & 1 & 9,1 \\
\hline \multirow[t]{4}{*}{$\begin{array}{l}\text { Geçirilen kaza/yaralanmadan } \\
\text { sonra yapılanlar }\end{array}$} & $\begin{array}{l}\text { Hiçbir şey } \\
\text { yapmadım }\end{array}$ & 4 & 33,3 \\
\hline & Acile başvurdum & 2 & 16,7 \\
\hline & $\begin{array}{l}\text { Gerekli tahlilleri } \\
\text { yaptırdım }\end{array}$ & 5 & 41,7 \\
\hline & $\begin{array}{l}\text { Pansuman } \\
\text { yaptırdım }\end{array}$ & 1 & 8,3 \\
\hline \multicolumn{4}{|l|}{ İşe bağlı hastalık geçirme } \\
\hline \multirow[t]{2}{*}{ Dermatit } & Evet & 11 & 11,5 \\
\hline & Hayır & 85 & 88,5 \\
\hline \multirow[t]{2}{*}{ Depresyon } & Evet & 4 & 4,2 \\
\hline & Hayır & 92 & 95,8 \\
\hline \multirow[t]{2}{*}{ Alerjik rinit } & Evet & 5 & 5,2 \\
\hline & Hayır & 91 & 94,8 \\
\hline \multirow[t]{3}{*}{ Boyun fitığı } & Evet & 4 & 4,2 \\
\hline & Hayır & 92 & 95,8 \\
\hline & Evet & 3 & 3.1 \\
\hline \multirow{2}{*}{ Varis } & Hayır & 93 & 96,9 \\
\hline & Evet & 1 & 1,0 \\
\hline Pnömoni & Hayır & 95 & 99,0 \\
\hline
\end{tabular}


Tablo 3'te sağlık çalışanlarının çalıştıkları kurumların bazı özellikleri görülmektedir. Katılımcıların \%94,8'i çalıştıkları kurumda yemekhane olmadığını, \%68,8'i çalıştıkları ortamda dinlenme odalarının olduğunu, \%69,8'i çalışma saatleri içerisinde mola hakkının olduğunu, \%63,5'inin çalıştıkları ortamda havalandırma yeterli, \%81,2'si aydınlatmanın yeterli olduğunu belirtmişlerdir. Kullanılan araç gereçlerin vücut ölçüleri için uygunluk durumları değerlendirildiğinde $\% 66,6$ 's yeterli olduğunu belirtmişlerdir.

\section{Tablo 3. Sağ|lk çalışanlarının çalıştıkları kurumların bazı özellikleri}

\begin{tabular}{lccc}
$\begin{array}{l}\text { Katıımcıların Çalıştıkları } \\
\text { Kurumlar }\end{array}$ & \multicolumn{3}{c}{} \\
\hline & & Sayı & Yüzde \\
\hline Yemekhane & Yok & 5 & 5,2 \\
Dinlenme odası & Var & 67 & 94,8 \\
& Yok & 29 & 69,8 \\
Mola hakkı & Var & 67 & 69,2 \\
& Yok & 29 & 30,2 \\
Havalandırma durumu & Yeterli & 61 & 63,5 \\
& Yeterli değil & 18 & 18,8 \\
& İdare eder & 17 & 17,7 \\
Aydınlatma durumu & Yeterli & 78 & 81,2 \\
& Yeterli değil & 9 & 9,4 \\
& İdare eder & 9 & 9,4 \\
Kullanılan araç-gereçlerin vücut & Uygun & 64 & 66,6 \\
ölçülerine uygunluğu & Uygun değil & 9 & 9,4 \\
& İdare eder & 23 & 24,0
\end{tabular}

Tablo 4'te sağlık çalışanlarının çalıştıkları kurumda şiddete maruz kalma durumları görülmektedir. Katılımcıların \%33,3'ü psikolojik şiddete maruz kaldıklarını belirtmişlerdir. Psikolojik şiddete maruz kaldıklarını belirten sağlık çaışanları şiddet uygulayanların \%50,0'sinin hasta ve hasta yakını olduğunu belirtirken, \%50,0'si sağlık çalışanı olduğunu ifade etmiştir. Katılımcıların \%7,3'ü fiziksel şiddete maruz kaldıklarını ifade ederken, $\% 85,4$ 'ü çalışılan kurumda alınan güvenlik önlemlerini yetersiz bulmuşlardır.

Tablo 5'te sağlık çalışanlarının mesleki yaşamlarına ilişkin özellikler görülmektedir. Katılımcıların \%77,1'i çalıştıkları kurumda iş sağlığı ve güvenliği ile ilgili hizmet içi eğitim aldıklarını, \%84,4'ü çalıştıkları kurumda iş sağlığı ve güvenliğinden sorumlu ekip olmadığını, \%50,6'sı mesleki risklerle ilgili çalıştıkları kurumun orta derecede önlem aldığını, \%79,1'i çalıştıkları kurumda koruyucu donanım kullanmayı gerekli olarak gördüklerini belirtmişlerdir.
Tablo 4. Sağlık çalışanlarının çalıştıkları kurumda şiddete maruz kalma durumları

\begin{tabular}{|c|c|c|c|}
\hline $\begin{array}{l}\text { Siddete maruz kalma } \\
\text { durumları }\end{array}$ & & Sayı & Yüzde \\
\hline $\begin{array}{l}\text { Psikolojik şiddete maruz } \\
\text { kalma durumu }\end{array}$ & $\begin{array}{l}\text { Evet } \\
\text { Hayır }\end{array}$ & $\begin{array}{l}31 \\
65\end{array}$ & $\begin{array}{l}33,3 \\
66,7\end{array}$ \\
\hline Psikolojik şiddeti uygulayan* & $\begin{array}{l}\text { Hasta ve hasta yakını } \\
\text { Sağlık çalışanı }\end{array}$ & $\begin{array}{l}4 \\
4\end{array}$ & $\begin{array}{l}50,0 \\
50,0\end{array}$ \\
\hline $\begin{array}{l}\text { Fiziksel şiddete } \\
\text { maruz kalma durumu }\end{array}$ & $\begin{array}{l}\text { Evet } \\
\text { Hayır }\end{array}$ & $\begin{array}{c}7 \\
89\end{array}$ & $\begin{array}{c}7,3 \\
92,7\end{array}$ \\
\hline Fiziksel şiddeti uygulayan** & $\begin{array}{l}\text { Hasta yakını } \\
\text { Hasta }\end{array}$ & $\begin{array}{l}3 \\
1\end{array}$ & $\begin{array}{l}75,0 \\
25,0\end{array}$ \\
\hline $\begin{array}{l}\text { Çalışılan kurumda alınan } \\
\text { güvenlik önlemleri }\end{array}$ & $\begin{array}{c}\text { Yeterli } \\
\text { Yeterli değil }\end{array}$ & $\begin{array}{l}14 \\
82\end{array}$ & $\begin{array}{l}14,6 \\
85,4\end{array}$ \\
\hline
\end{tabular}

Tablo 5. Sağlık çalışanlarının mesleki yaşamlarına ilişkin özellikler

\begin{tabular}{lccc} 
& & Sayı & Yüzde \\
\hline İ̧ sağlığı ve güvenliği ile ilgili & Evet & 74 & 77,1 \\
hizmet içi eğitim alma durumu & Hayır & 22 & 22,9 \\
İş sağlığı/güvenliğinden sorumlu & Evet & 15 & 15,6 \\
ekip olma durumu & Hayır & 81 & 84,4 \\
Mesleki risklerle ilgili çalıştıkları & Çok iyi & 3 & 3,2 \\
kurumun önlem alma düzeyi & İyi & 28 & 29,5 \\
& Orta & 48 & 50,6 \\
& Kötü & 15 & 15,8 \\
& Çok kötü & 1 & 1,1 \\
Koruyucu ekipman kullanmayı & Evet & 76 & 79,1 \\
gerekli görme durumu & Hayır & 20 & 20,8
\end{tabular}

\section{Tartışma}

Bu çalışmada birinci basamak sağlık hizmetlerinde çalışan sağlıkçıların sağlıkları ve çalıştıkları ortamdaki risk etmenleri değerlendirilmiştir. Katıımcıların \%42,7'si bulundukları kurumda 8-11 yıl arasında çalıştıklarını belirtmişlerdir. Eğitim, çalışma süresi, cinsiyet, yaş ve medeni durum iş memnuniyetini etkilemektedir. Aile sağlığı çalışanları ile yapılan bir çalışmada çalışma yılı 10 yıl ve üzeri olan, kadın, bekâr, ebe olarak çalışan bireyler ile 31 yaş ve üzerinde olan bireylerin aile sağlığı elemanı olarak çalışmaktan daha az memnun oldukları belirlenmiştir (14).

Sağlık çalışanları için aşılama, mesleki maruziyet riskinin fazla olması ve duyarlı hastalarla karşılama tehlikesinin bulunması açısından önemlidir (18). Ayrıca aşılanmanın yanında düzenli periyotlarla serolojik testlerin yapılarak sağlık çalışanlarının bağışıklık durumunun izlenmesi de 
gereklidir. Aynı zamanda tetanos ve difteri gibi aşıların antikor düzeyleri yaşla birlikte azalabilmektedir. Dolayısıyla bu aşıların rapellerinin uygun aralıklarla yapılması da gereklidir (19). Bu araştırmada katılımcıların BCG $(\% 65,6)$, hepatit B $(\% 89,6)$, tetanoza $(\% 89,6)$ karşı bağışıklığı bulunmaktadır (Tablo 1). Yunanistan'da yapılan bir çalışmada sağlık çalışanlarının \%55,7'si hepatit B'ye karşı, \%47,3'ü tetanoz-difteriye karşı aşılandıklarını belirtmiştir (18). Bu çalışmada sağlık çalışanlarının aşılanma oranları dünyada ve Türkiye'de ki sağlık çalışanlarının aşılanma oranlarından yüksek bulunmuştur. Bu sonuçta katılımcıların birinci basamakta çalışıyor olmasının, aşılanma hakkında topluma danışmanlık yapmalarının etkili olduğu düşünülmektedir.

Sağlık çalışanları yaptıkları işten ya da yaşam alışkanlıklarından kaynaklı bazı sağlık sorunları yaşayabilmektedirler. Bu sorunlardan biri de kronik hastalıklardır. Sağlık çalışanlarının \%27,1'inin kronik hastalığı olduğu belirlenmiştir (Tablo 1). Yapılan bir çalışmada sağlık çalışanlarında kronik hastalık varlığının düşük düzeyde olduğu belirlenmiştir (5). Sonuçlar bu çalışmanın sonuçları ile benzerlik göstermektedir. Bununla birlikte sağlık personelinin sağlık hizmeti verirken karşılaştıkları iş risklerinin kronik hastalıklarla ilişkisini ortaya koyan çalışmalara ihtiyaç olduğu da düşünülmektedir.

Bu araştırmada katılımcıların \%12,5'i 1. Basamakta kaza yaralanma geçirmiş, \%90,9'u kesici-delici alet yaralanması geçirmiş, \%9,1'i ambulansla vakaya giderken kaza geçirmiş, kaza yaralanma geçirdikten sonra \%33,3'ü hiçbir şey yapmazken, \%41,7'si gerekli tahlilleri yaptırmıştır (Tablo 2). Hemşirelerle yapılan bir çalışmada da katılımcıların $\% 17,5^{\prime} i$ kontamine bir biyolojik materyale maruz kaldıklarını belirtirken, bunların $\% 61,5^{\prime} i$ perkütan yaralanmalar şeklindedir (11). Sağlık çalışanları ile yapılan bir çalışmada da katılımcıların \%48,1'i kesici-delici alet yaralanması geçirmiştir (10). Başka bir çalışmada da en fazla iğne ucu, intravenöz kateterler ve sütur atma sırasında bir kesici-delici alet ile kaza/yaralanmaya maruz kaldıkları belirlenmiştir (20). Bu araştırmada sağlık çalışanlarının en fazla kaza/ yaralanma geçirme nedeninin kesici/delici alet yaralanmaları olması yapılan çalışmalarla benzerlik göstermektedir. Yapılan bir çalışmada, katılımcılar yaralanma sonrası bölgeyi antiseptik solüsyon ile $(\% 77,8)$ yıkamış, yalnızca \%66,0'sı kaza/yaralanmayı bildirmiştir (20). Bu araştırmada sağlık çalışanlarının kaza/yaralanmayı bildirim oranları literatürle benzerlik göstermektedir.

Bu araştırmada sağlık çalışanları işe bağlı hastalık geçirme durumlarını \%15,6 olarak belirtirken, $\% 11,5^{\prime} \mathrm{i}$ dermatit, \%4,2'si depresyon, \%4,2'si boyun fıtığı, \%3,1'i varis, \%5,2'si alerjik rinit geçirdiklerini belirtmişlerdir (Tablo 2). Bir çaıışmada katılımcıların son bir yıl içerisinde el egzaması geçirme oranı $\% 21,0$ olarak belirtilmiş ve egzama ile ilişki en önemli faktörlerden birisi dermatit olarak belirtilmiştir (21). Sağlık çalışanları ile yapılan bir çalışmada işe bağlı bir cilt hastalığı görülme oranı \%55,5 olarak belirlenmiş ve bunların önemli bir kısmının dermatit vakaları olduğu bildirilmiştir (9). Bu araştırmada dermatit geçirenlerin oranının yapılan çalışmalara göre düşük düzeyde bulunması uygun el antiseptikleri ve uygun malzeme ile üretilmiş eldiven kullanılmasına bağlı olabileceği düşünülmektedir. Sağlık çalışanları ile yapılan bir çalışmada uzun süreler boyunca ve sık sık aynı ya da uygun olmayan bir pozisyonda çalışmanın ve bakılan hasta sayısının artması sonucunda sırasıyla bel ağrısı $(\% 45,7)$, boyun ağrısı $(\% 28,5)$ ve omuz ağrısı $(\% 23,5)$ deneyimledikleri belirlenmiştir (7). Hemşirelerle yapılan bir başka çalışmada da \%63,3'ü çalışma ortamından kaynaklanan herhangi bir kas iskelet sistemi rahatsızlığına sahip olduğunu belirtmişlerdir (4). Bu araştırmada sağlık çalışanlarının boyun fıtığı geçirme durumları diğer çalışmalara göre düşük düzeyde bulunmuştur. Bunun nedenleri çalışanların ergonomi eğitimleri almış olması olabileceği düşünülmektedir. Çin'de doktorlarla yapılan bir çalışmada depresyon sıklığının fazla olduğu belirlenmiştir (22). Bu araştırmanın sonucunda sağlık çalışanlarının işe bağıı olarak depresyon geçirme durumları bu çalışmaya göre düşük düzeydedir. Kesgin ve Kublay tarafından yapılan bir çalışmada katıımcıların varis $(\% 5,9)$ ve alerjik bir yakınmasının $(\% 41,8)$ olduğu belirlenmiştir (10). Bu araştırmada da sağlık çalışanlarının varis geçirme durumları Kesgin ve Kublay'ın çalışması ile benzerlik göstermektedir.

Çalışma ortamında kullanılan araç gereçlerin ergonomik olmasının çalışma verimini artırdığı, iş kazalarını azalttığı, yaşam kalitesi algısını olumlu etkilediği bilinmektedir $(5,6)$. Bu araştırmada katılımcıların tamamına yakınının çalıştıkları kurumda yemekhane bulunmazken $(\% 94,8)$, $\% 68,8$ i çalıştıkları ortamda dinlenme odalarının olduğunu, \%69,8'i çalışma saatleri içerisinde mola hakkının olduğunu, $\% 63,5^{\prime} \mathrm{i}$ çalıştıkları ortamda havalandırma yeterli, $\% 81,2$ 'si aydınlatmanın yeterli olduğunu belirtmişlerdir (Tablo 3). Katılımcıların \%66,6'sı kullanılan araç gereçlerin vücut ölçüleri için uygun olduğunu belirtmişlerdir. Güler ve ark. tarafından yapılan bir çalışmada da hasta bakımı için kullanılan alan ve malzemelerin rahat çalışabilmek açısından kısmen uygun olduğunu ve \%76,7'si çalışma saatleri içerisinde dinlenme molalarının olduğunu belirtmiştir (4). Hemşirelerle yapılan bir çalışmada da aydınlatma $(\% 66,7)$, havalandırma $(\% 52,7)$, temizlik $(\% 80,0)$, kullanılan hemşire deskinin kullanışlıı̆ı $(\% 65,3)$ oranında 
yeterli bulunmuştur (23). Asm (Aile Sağlığı Merkezi)'de çaIışan sağlık çalışanları ile yapılan bir çalışmada da \%73,5'i Asm'nin fiziki koşulları sağladığını, \%70,0'i Asm'nin fiziki koşullarından memnun olduğunu belirtmişlerdir (14). Bu araştırmada sağlık çalışanlarının kurumlarında ki fiziksel koşulları iyi olarak değerlendirmelerinin hem iş sağlığı ve güvenliği açısından hem de bu kurumlara başvuran bireyler açısından olumlu sonuçlar doğuracağı düşünülmektedir.

Aile hekimleri ile yapılan bir çalışmada katıımcılar iş yükü fazlalığı, gereksiz iş yükü, yetersiz fiziksel koşullarla ilgili sorunların yanında hasta kaynaklı tutum ve davranışlar ile ilgili sorunlar yaşadıklarını belirtmişlerdir. Aynı çalışmada katılımcıların \%23,9'u hasta ve yakınları tarafından uygulanan olumsuz bir davranışla karşılaşmış ve bu durumun tükenmişlik ve duyarsızlaşmayı artırdığı belirlenmiştir (24). Bu araştırmada sağlık çalışanlarının \%33,3'ü psikolojik şiddete maruz kaldıklarını belirtmişlerdir. Psikolojik şiddete maruz kaldıklarını belirten sağlık çalışanları şiddet uygulayanların \%50,0'sinin hasta ve hasta yakını olduğunu belirtirken, \%50,0'si sağlık çalışanı olduğunu ifade etmiştir. Katılımcıların \%7,3'ü fiziksel şiddete maruz kaldıklarını ifade ederken, \%85.4'ü çalışılan kurumda alınan güvenlik önlemlerini yetersiz bulmuşlardır (Tablo 4). Çin'de kamu sağlığı merkezinde çalışan sağlık çalışanları ile yapılan bir çalışmada katılımcıların \%51,6'sının iş yerinde şiddete maruz kaldıkları belirlenmiştir. Şiddetin \%9,6'sı fiziksel şiddet, \%23,0'ü tehdit, \%46,2'si psikolojik şiddet, \%10,5'i sözlü cinsel taciz, $\% 4,3$ 'ü cinsel saldırı şeklindedir (13). Sağlık çalışanları ile yapılan bir çalışmada sağlık personelinin \%14,0'ü kırsal alanda can güvenliğinin olmamasını hemşirelerin kurum yönetiminden kaynaklanan sorunları arasında daha fazla belirtmişlerdir (12). Bu araştırmanının sonuçları Türkiye ve dünyada yapılan çalışmalarla benzerlik göstermektedir. Yapılan çalışmalarda iş yerinde şiddetin sebepleri arasında şiddeti bildirmek için teşvik edici bir ortamın bulunmaması ve şiddete maruz kalanların şiddeti bildirmenin faydasız olduğuna inanmaları yer almaktadır $(25,26)$. Iş̧yerinde şiddetin yaşam kalitesi ve iş performansını olumsuz olarak etkilediği, şiddete maruz kalan sağlık çalışanlarında yüksek iş yükü, düşük destek, düşük algılanan örgütsel adalet ve yüksek psikolojik sıkıntıya neden olduğu belirtilmiştir (13).

Bu araştırmada katılımcıların \%77,1'i çalıştıkları kurumda iş sağlığı ve güvenliği ile ilgili hizmet içi eğitim aldıklarını, \%84,4'ü çalıştıkları kurumda iş sağlığı ve güvenliğinden sorumlu ekip olmadığını, \%50,6'sı mesleki risklerle ilgili çalıştıkları kurumun orta derecede önlem aldığını, \%79,1'i çalıştıkları kurumda koruyucu donanım kullanmayı gerekli olarak görmektedir (Tablo5). Yazıcı ve Kalaycı tarafından yapılan bir çalışmada hemşirelerin \%50,7'si hizmet içi eğitimleri yeterli olarak değerlendirmiştir (23). Sağlık çalışanları ile yapılan bir çalışmada da katılımcıların sadece yarısı iş sağlığı ile ilgili eğitim aldıklarını belirtmiş̧lerdir (20). Bu araştırmada katılımcılar hizmet içi eğitim alma durumlarını yapılan çalışmalara göre yüksek olarak değerlendirmiştir. Bu sonucun toplum sağlığı ve aile sağlığı yöneticilerinin iş sağlığı ve güvenliği eğitimlerine gereken önemi göstermeleri ile ilgili olabileceği düşünülmektedir. Sağlık çalışanları ile yapılan bir çalışmada doktorlar sağlık taraması ve kayıtlar, koruyucu önlem ve kurallar, malzeme, araç, gereç denetimi, fiziksel ortam konularında, hemşireler ise meslek hastalıkları ve şikâyetler boyutunda iş sağlığı ve güvenliği uygulamalarını yetersiz bulduklarını belirtmişlerdir. Aynı çalışmada hemşirelerin \%49,0'u iş kazası/meslek hastalığına ilişkin olarak hastanenin sorumluluk alma ve desteğinden, hekimlerin ise $\% 51,0$ 'i iş güvenliğine yönelik eğitimlerden memnun değildir (27). Bu araştırmada mesleki risklerle ilgili önlem alma durumu literatürle benzerlik göstermektedir. Kişisel koruyucu kullanımının, hizmet içi eğitimlerin sağlık çalışanlarının sağlığını korumada etkili uygulamalardan olduğu belirtilmiştir. Kesici- delici alet yaralanmalarına maruz kalan sağlık personelleri ile yapılan bir çalışmada katılımcıların \%55,1'inin maruziyet sırasında koruyucu donanım kullandığı belirlenmiştir (28). Benzer bir çalışmada da sağlık çalışanlarının maruz kalma sırasında \%74,1'inin kişisel koruyucu donanım kullandığı belirlenmiştir (29). Kişisel koruyucu donanım kullanma durumu yapılan çalışmalarla benzerlik göstermektedir.

\section{Sonuçlar ve öneriler}

Birinci basamak sağlık çalışanlarının çalıştıkları kurumda ergonomik sorunlar yaşadıkları, çoğunlukla kesici-delici alet yaralanmasına maruz kaldıkları belirlenmiştir. Çalışılan kurumların mesleki risklerle ilgili önlem alma durumu orta düzeydedir ve kurumların büyük çoğunluğunda iş sağlığı ve güvenliğinden sorumlu ekip yoktur. Sağlık çalışanlarının psikolojik şiddet maruz kalma oranları önemli düzeydedir. Birinci basamakta çalışan sağlık çalışanları meslek hayatları boyunca farklı risklere maruz kalmaktadır. Risk etmenlerinin belirlenmesine yönelik olarak kurumların gereken önlemleri alması sağlık çalışanlarına yönelik hizmet içi eğitimler önem kazanmaktadır. 


\section{Kaynaklar}

1. Bilir N, Yıldız AN. Halk Sağlığı Temel Bilgiler. İçinde: Çağatay G, Levent A, editörler. İş Sağlığı ve Güvenliği 3. Baskı. Ankara: Hacettepe Üniversitesi Yayınları; 2015. pp.1070-1.

2. Çalışma ve Sosyal Güvenlik Bakanlığı 2017. iş Sağlığı ve Güvenliğine İlişkin İşyeri Tehlike Sınıfları Tebliğinde Değişiklik Yapılmasına Dair Tebliğ. Erişim: http://www.resmigazete.gov.tr/ eskiler/2017/02/20170227M1-1.htm

3. World Health Organization (WHO). Health Workers -Health worker occupational health Erişim: http://www.who.int/ occupational_health/topics/hcworkers/en/

4. Güler T, Yıldız T, Önler E, Yıldız B, Gülcivan G. Hastane Ergonomik Koşullarının Hemşirelerin Mesleki Kas İskelet Sistemi Rahatsızlıkları Üzerine Etkisi. Int Anatolia Acad Online J 2015;3.

5. Aras D, Uskun E. Hemşirelerin Çalışma Ortamı Riskleri ve Yaşam Kalitesi ile Illişkisi. Tıp Araş Derg 2015;13:62-9. [CrossRef]

6. Babayiğit MA, Kurt M. Hastane Ergonomisi. Istanbul Med J 2013;14:153-9. [CrossRef]

7. Yasobant S, Rajkumar P. Work-Related Musculoskeletal Disorders Among Health Care Professionals: A Cross-Sectional Assessment of Risk Factors in a Tertiary Hospital, India. Indian J Occup Environ Med 2014;18:75. [CrossRef]

8. Connor TH, Lawson CC, Polovich M, McDiarmid MA. Reproductive Health Risks Associated with Occupational Exposures to Antineoplastic Drugs in Health Care Settings: A Review of the Evidence. J Occup Environ Med 2014;56:901-10. [CrossRef]

9. Higgins $\mathrm{CL}$, Palmer $\mathrm{AM}$, Cahill JL, Nixon RL. Occupational Skin Disease Among Australian Healthcare Workers: A Retrospective Analysis From an Occupational Dermatology Clinic, 1993-2014. Contact Dermatitis 2016;75:213-22. [CrossRef]

10. Kesgin MT, Kublay G. Özel Bir Hastanede Çalışan Hemşirelerin Yaşam Alışkanlıkları ve Çalışma Koşullarından Kaynaklı Sağlık Sorunlarının Değerlendirilmesi. Hacettepe Üniv Hem Fak Derg 2011;18:41-9. Erişim: $\quad$ http://www.hacettepehemsirelikdergisi.org/pdf/pdf HHD_111.pdf

11. Negrinho NB, Malaguti-Toffano SE, Reis RK, Pereira FMV, Gir E. Factors Associated with Occupational Exposure to Biological Material Among Nursing Professionals. Rev Bras Enferm 2017;70:133-8. [CrossRef]

12. Öztürk H, Candaş B, Babacan E. Devlet Hastaneleri, Toplum ve Aile Sağlığı Merkezlerinde Çalışan Hemşirelerin Yaşadıkları Sorunların Belirlenmesi. Sağlık Hem Yön Derg 2015;2:25-36. [CrossRef]

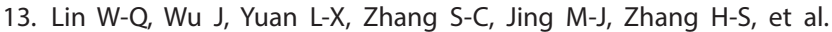
Workplace Violence and Job Performance among Community Healthcare Workers in China: The Mediator Role of Quality of Life. Int J Environ Res Pub Health 2015;12:14872-86. [CrossRef]

14. Sonmez MO, Sevindik F. The Effect of Transformation in Health on Health Personnel; To be Family Health Personnel. TAF Prev Med Bull 2013;12:43-8.
15. Crisp N, Chen L. Global supply of health professionals. New Engl J Med 2014;370:950-7. [CrossRef]

16. Akman M. Türkiye'de Birinci Basamağın Gücü. Türkiye Aile Hek Derg 2014;18:70-8. [CrossRef]

17. Lemeshow S, Hosmer D, Klar J, Lwanga S. Adequacy of Sample Size in Health Studies by World Health Organization. Oguz Kayaalp SO, çeviri. Ankara: Hacettepe Taş; 2000.

18. Maltezou HC, Katerelos P, Poufta S, Pavli A, Maragos A, Theodoridou M. Attitudes Toward Mandatory Occupational Vaccinations and Vaccination Coverage Against Vaccine-Preventable Diseases of Health Care Workers in Primary Health Care Centers. Am J Infect Cont 2013:41:66-70. [CrossRef]

19. Cılız N, Gazi H, Ecemiş T, Şenol Ş, Akçalı S, Kurutepe S. Sağlık Çalışanlarında Kızamık, Kızamıkçık, Kabakulak, Suçiçeği, Difteri, Tetanos ve Hepatit B Seroprevalansı. Klimik J / Klimik Derg 2013;25. [CrossRef]

20. Kaur D, Jaspal S, Bajwa SJS. Behavior, Perception and Compliance Related to Adoption of Safety Measures in Response to Needle Stick Injuries Among Nursing Personnel at a Tertiary Care İnstitute of North India. J Sci Society 2014;41:32-7. [CrossRef]

21. Ibler KS, Jemec GB, Garvey LH, Agner T. Prevalence of Delayed-Type and Immediate-Type Hypersensitivity in Healthcare Workers with Hand Eczema. Contact Dermatitis 2016;75:223-9. [CrossRef]

22. Gong Y, Han T, Chen W, Dib HH, Yang G, Zhuang R, et al. Prevalence of anxiety and depressive symptoms and related risk factors among physicians in China: a cross-sectional study. PloS ONE 2014;9:e103242. [CrossRef]

23. Özbek Yazıcı S, Kalaycı I. Hemşirelerin çalışma ortam ve koşullarının değerlendirilmesi. SDÜ Müh Bilim Tasarım Derg 2015;3:379-83. Erişim: https://dergipark.org.tr/download/article-file/195476

24. Şerik B, Erdoğan N, Ekerbiçer HÇ, Demirbaş $M$, İnci BM, Bedir N, et al. Sakaryada Aile Sağlığı Merkezlerinde Çalışan Aile Hekimlerinin Tükenmişlik Düzeyleri ve İlişkili Faktörler. Sakarya Tıp Derg 2016;6:76-82. [CrossRef]

25. Fisekovic Kremic MB, Terzic-Supic ZJ, Santric-Milicevic MM, Trajkovic GZ. Encouraging employees to report verbal violence in primary health care in Serbia: A cross-sectional study. Zdr Varst 2017;56:11-7. [CrossRef]

26. Al-Turki N, Afify AA, AlAteeq M. Violence against health workers in Family Medicine Centers. J Multidiscip Healthc 2016;9:257-66. [CrossRef]

27. Öztürk H, Babacan E, Özdeş Anahar E. Hastanede Çalışan Sağlık Personelinin İ̧̧ Güvenliği. GÜSD 2012;1. Erişim: http://dergipark. ulakbim.gov.tr/gumussagbil/article/view/5000003594/5000004108

28. Kepenek E, Şahin-Eker HB. Bir Devlet Hastanesinde Çalışanlarda Meydana Gelen Kesici ve Delici Alet Yaralanmalarının Değerlendirilmesi. Klimik J / Klimik Derg 2017;30:78-82. [CrossRef]

29. Ünsal G, Erbay A, Ișlak Demir M, Kader C.. Bozok Üniversitesi Hastanesi Sağlık Çalışanlarında Kan ve Vücut Sıvılarıyla Illişkili Maruziyetlerin Değerlendirilmesi. Gazi Med J 2015;26. 